\title{
Perspectives on water flow and the interpretation of FLIR images
}

\author{
S. L. LARSON, L. L. LARSON, AND P. A. LARSON
}

Authors are NASA EPSCoR Postdoctoral Research Associate, Department of Physics, Montana State University, Bozeman, Mont. 59717; Professor, Department of Rangeland Resources, Oregon State University, Corvallis, Ore. 97331; Forester, La Grande, Ore. 97850.

\begin{abstract}
Airborne infrared thermal radiography has been proposed as a tool which may be used to monitor the water temperature along the network of streams and rivers which compose a watershed. The proponents of this method correlate vegetative shadows on a stream channel with reduced infrared radiation (IR) reception in the radiographic data to suggest that the water temperature is reduced in such areas.

Two methods are employed to demonstrate that this interpretation of the data is in error. First, the fundamental principles of thermodynamics are employed to show that if the stream is in fact flowing, the water affected by any cooling process cannot remain in the vicinity where it was cooled. Second, temperature data taken from a stream channel are used to show that the water flowing in the channel is essentially unaffected by the patterns of vegetative shade on the surface of the channel.
\end{abstract}

Key Words: Water flow, stream temperature, FLIR imaging

Current efforts to combat reductions in salmon populations in the Columbia River Basin have led to the development of a wide variety of water management plans in the composite watersheds which seek to address issues relating to the water quality in fish habitats. At the heart of many of these plans is a desire to control the temperature of the streams in a watershed, since elevated water column temperature is the single most common water-quality violation for streams in the Pacific Northwestern states (Clean Water Act 303(d) listings for Washington, Oregon and Idaho). In each case, water temperature management must be addressed through the Total Maximum Daily Load (TMDL) provision of the Clean Water Act.

To monitor the stream temperatures in many watersheds, FLIR (Forward Looking Infrared Radiometer) imagery is being employed as a method of monitoring and directly measuring temperatures on a stream. A sample FLIR image, a paired aerial photograph taken at the same time, and the estimated water temperatures implied by the FLIR image are shown in Figure 1 (Oregon Department of Environmental Quality (1999a)). Proponents of FLIR monitoring suggest that the correlation between the white light shadows in the aerial photograph and the change in infrared signature in the FLIR data demonstrates the cooling effect of shade on the stream.

Manuscript accepted 14 Apr. 01.
Resumen

La radiografía térmica infrarroja transmitida por aire ha sido propuesta como una herramienta la cual puede ser utilizada para monitorear la temperatura del agua a lo largo de la red de corrientes y ríos que componen una cuenca hidrológica. Los proponentes de este método correlacionan las sombras vegetativas sobre el canal de la corriente con una recepción reducida de radiación infrarroja (IR) en los datos radiográficos para sugerir que la temperatura del agua es reducida en tales áreas.

Se emplearon dos métodos para demostrar que esta interpretación de los datos esta equivocada. Primero, los principios fundamentales de la termodinámica son empleados para mostrar que si la corriente esta fluyendo, el agua afectada por cualquier proceso de enfriamiento no puede permanecer en la vecindad de donde fue enfriada. Segundo, datos de temperatura tomados de un canal de corriente son usados para mostrar que el agua fluyendo en el canal esencialmente no es afectada por los patrones de sombra vegetativa sobre la superficie del canal.

This paper considers the time it takes a body of water to cool, and explores how the signature of resulting temperature change should manifest itself in a wide area monitoring system, such as FLIR. This is shown in 2 ways: first, through a theoretical analysis based on fundamental principles of thermodynamics, and second, through collection of column temperature data directly in the water of an area similar to that shown in Figure 1.

The paper is organized in 7 parts, as follows. The effect of the flow rate on the water is analyzed to show that the coolest 'temperatures' in the FLIR images should not correspond exactly with the shaded regions in the companion aerial photograph. Examples of using the theoretical results are given, and data taken directly from a partially shaded stream is presented to show the error in the interpretation of the FLIR images. Finally, speculations are offered as to the cause in the misinterpretation of the FLIR data, and summary and conclusions are presented. An appendix presents a rigorous derivation of the mathematical results presented in the paper.

\section{The Effect of Water Flow on Temperature Profiles}

If water is to be cooled in any thermodynamic system (e.g., in a stream in a watershed), one must first determine how much heat energy must be dissipated to obtain the desired temperature, and 


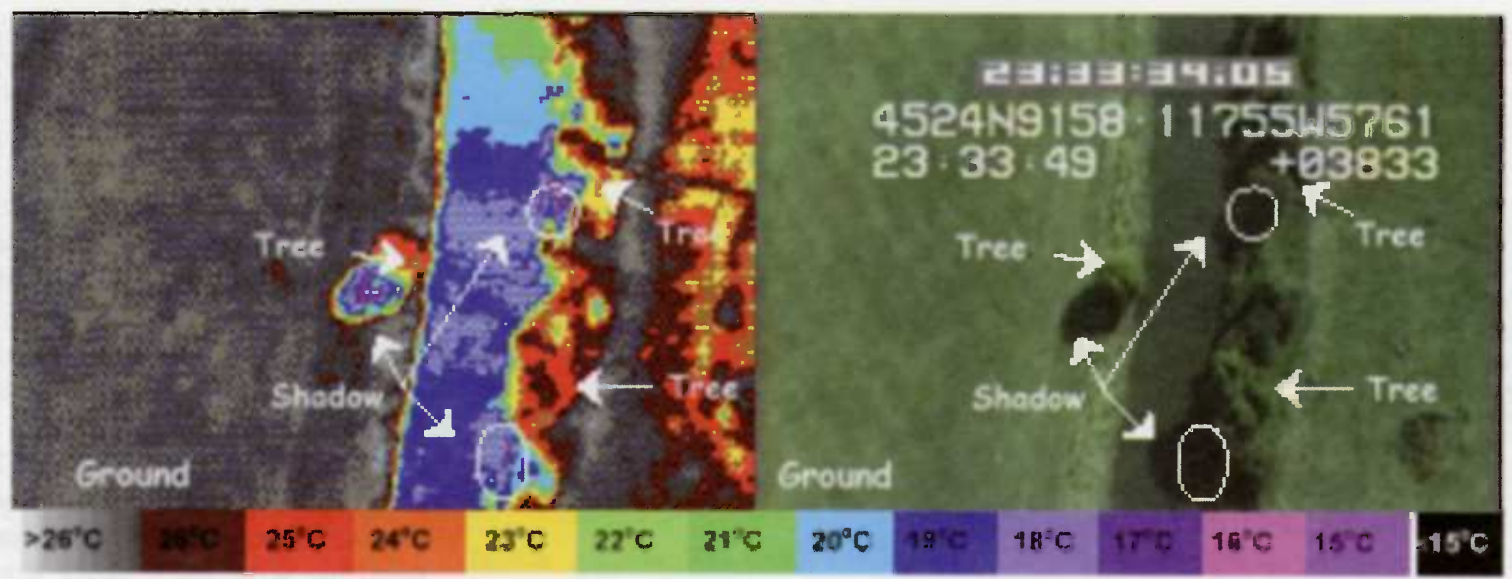

Fig. 1. An example of FLIR data and the accompanying temperature scale interpretation from the Oregon Department of Environmental Quality. The claim is that the mixed water column in the shade of the shoreline vegetation is cooler than water in open sunlight, evidenced by the correlation between shadows in the aerial photograph and a drop in the infrared signal of the FLIR data in the same region. On the scale of the photograph, this change occurs over several meters (e.g., near the lower ellipse, the temperature is shown as $\mathrm{T}_{i}=19^{\circ} \mathrm{C}$ in the open water, but at the center of the ellipse is $T_{f}=17^{\circ} \mathrm{C}$ ).

secondly one must account for the transfer of this heat out of the system (i.e., out of the water). These quantities can be determined using standard, basic principles from thermodynamics (see, for example, Serway (1997), or Halliday and Resnick (1988))

To conduct this analysis, one needs to use 2 quantities together: the total heat energy to be removed, $Q$, and the rate of heat flow, $H$. For a given change in temperature, $\Delta T=T_{f}-T_{i}$, the amount of heat which must be removed from the system is given by

$$
Q=c m \Delta T=c m\left(T_{f}-T_{i}\right)
$$

where $Q$ is the heat energy, $c$ is the specific heat of the material, $\mathrm{m}$ is the mass of the material, and $T_{f}$ and $T_{i}$ are the final and initial temperatures of the system. The transfer of heat energy out of a system cannot occur instantaneously; it takes a finite amount of time and depends on the thermal conductivity of the surrounding environment. The heat energy is conducted away from the system and dumped into some thermal reservoir which is at constant temperature, $T_{r}$. The rate, $H$, at which heat can be conducted out of a system and deposited in the reservoir is given by

$$
H=\frac{Q}{\Delta t}=k A \frac{\left(T_{i}-T_{r}\right)}{d}
$$

where $Q$ is the total heat energy (computed from Eq. 1) which must be conducted away, $\Delta t$ is the time it takes the heat to flow away, $k$ is the thermal conductivity of the medium connecting the system to the reservoir where the heat is dissipated, $A$ is the surface area at the interface between the system and the conducting medium, $\mathrm{d}$ is the distance over which the heat must be conducted, $T_{i}$ is the temperature of the system being cooled (or heated), and $T_{r}$ is the temperature of the thermal reservoir where the heat is being dissipated. Note that when $T_{i}>T_{r}$, heat energy flows out of the system (e.g., out of a body of water and into a thermal reservoir, with $H>0$ ). When $T_{i}<T_{r}$, heat energy flows into the system (e.g., into a body of water from the thermal reservoir, with $H<0$ ).

By substituting the expression for $Q$ from Eq. (1) into Eq. (2), one can use algebra to solve for the time, $\Delta t$, it would take to dissipate the heat energy in the water, yielding

$$
\Delta t=\frac{m c d}{k A} \frac{\left(T_{f}-T_{i}\right)}{\left(T_{i}-T_{r}\right)}
$$

The time, $\Delta t$, is the key element in determining how the flow of the water should affect the thermal profile of the stream. The speed $v$ with which the water flows over a given horizontal distance is related to the time by

$$
v=\frac{\ell}{\Delta t} \Rightarrow \Delta t=\frac{\ell}{v}
$$

Substituting this into Eq. (3), and solving for $\ell$ yields

$$
\ell=\frac{v m c d}{k A} \frac{\left(T_{f}-T_{i}\right)}{\left(T_{i}-T_{r}\right)}
$$

For the application of interest (the transfer of heat energy in a stream), it is useful to cast this result in terms of parameters which describe the physical characteristics of the stream by eliminating the mass $m$ in Eq. (5). The mass can be expressed in terms of the density of water, $\rho$, and the volume of the stream being considered, $V$ $=h A$, where $h$ is the depth of the stream channel. With these 2 quantities, the mass can be written as

$$
m=\rho V=\rho h A
$$

Substituting this into Eq. (5), one arrives at the final expression for the distance $\ell$ :

$$
\ell=c \rho \frac{v h d}{k} \frac{\left(T_{f}-T_{i}\right)}{\left(T_{i}-T_{r}\right)}
$$

This is the distance over which a body of water of depth $h$ will cool from a temperature $T_{i}$ to a temperature $T_{f}$ if it is connected to a thermal reservoir (heat dump) at temperature $T_{r}$. The connection is made through a conducting body with a depth $\mathrm{d}$ and a thermal conductivity $k$. Since cooling processes are being considered, the value for computed from Eq. (7) will always be negative (since $T_{f}<T_{i}$ and $T_{i}>$ $T_{r}$ ); the absolute value should be taken to give a proper, measurable distance.

\section{An Example of Water Cooling}

Let us consider the implications of the result presented in Eq. (7). Consider a stream, described by the physical parame- 
Table 1: Example Physical Stream Parameters

\begin{tabular}{lcl}
\hline \hline Quantity & Symbol & Value \\
\hline Depth & $h$ & $0.5 \mathrm{~m}$ \\
Flow Rate & $\mathrm{v}$ & $0.25 \mathrm{~m} / \mathrm{s}$ \\
Initial water temperature & $T_{i}$ & $21^{\circ} \mathrm{C}$ \\
Final water temperature & $T_{f}$ & $20^{\circ} \mathrm{C}$ \\
Conduction depth & $d$ & $1 \mathrm{~m}$ \\
Thermal conductivity (granite) & $k$ & $2.5 \mathrm{~W} /\left(\mathrm{m}^{\circ} \mathrm{C}\right)$ \\
Thermal reservoir temperature & $T_{r}$ & $15^{\circ} \mathrm{C}$ \\
Density of water & $\rho$ & $1000 \mathrm{~kg} / \mathrm{m}^{\circ}$ \\
Heat capacity of water & $\mathrm{c}$ & $4190 \mathrm{~J} /\left(\mathrm{kg}{ }^{\circ} \mathrm{C}\right)$ \\
\hline
\end{tabular}

ters given in Table 1. Since fine sediments are considered to be detrimental in salmonid habitats, the streambed is assumed to be coarse granitic substrate.

Using these numbers to evaluate Eq. (7), water which is cooled solely by interaction with the streambed requires a distance of $\ell$ $35 \mathrm{~km}$ to cool the stream by $1^{\circ} \mathrm{C}$.

Another possible thermal reservoir where heat could be deposited is the atmosphere. If the atmosphere is cooler than the water, heat energy will flow from the stream surface and dissipate into the air. The methods outlined here may again be used to estimate the distance the water will traverse before the atmosphere could cool it by a single degree Centigrade. Assume that the air reservoir maintains a constant temperature of $T_{r}=15^{\circ} \mathrm{C}$, and is separated from the stream by a $d=1 \mathrm{~m}$ thick conducting zone. Air is a relatively poor thermal conductor, with a thermal conductivity of $k=0.026 \mathrm{~W} /\left(\mathrm{m}^{\circ} \mathrm{C}\right)$. Using these numbers, water cooled solely by interaction with the atmosphere over a distance of $10 \mathrm{~m}$ would cool only by $2.98 \mathrm{x}$ $10^{-6}{ }^{\circ} \mathrm{C}$; small fractional changes in temperature such as this are all but undetectable using field equipment.

\section{Implications for FLIR Data Analysis}

The implications of this result have important consequences for the interpretation of FLIR data. As indicated in Figure 1 , the current analysis procedures using FLIR data exactly correlate the shadows in an aerial photograph with regions of supposed cooler stream temperatures. In Figure 1, the data scale would imply that stream temperatures drop by an amount $\Delta \mathrm{T} \sim 1^{\circ} \mathrm{C}$ to $2^{\circ} \mathrm{C}$ over the course of approximately 2 meters (the distance between open sunlight and fully shaded areas). Based on the analysis presented above, this cannot be the case, since the fact that the water flows implies that the cooler temperatures should lie some dis- tance $\ell$ downstream from the cooling influences.

To reconcile these differences, actual water column temperatures were measured on a stream, to better understand what differences should be observed between the sunlit and shaded areas.

Data was collected over 2 clear days with no clouds, during late summer when the solar angle was $\sim 54^{\circ}$ at noon standard time. Ten data-logging thermisters (Onset Computer Corp., Pocasset, Mass.) were distributed along a partially shaded stream channel, as shown in Figure 2. The thermisters were spaced 3 meters apart, and suspended $25 \mathrm{~cm}$ below the water's surface, to measure the temperature of the protocol was followed with thermister validation occuring at 2 known temperatures; stowaway temperature loggers have a mixed water column. Standard thermister thermisters from light to shade. manufacturer specified accuracy of $\pm 0.2^{\circ}$ $\mathrm{C}$ and recorded temperatures at 1 hour intervals. The approximate flow rate of the water was $0.3 \mathrm{~m} / \mathrm{s}$ and was estimated using a pygmy flow meter. Over the course of the day, the Sun tracked across the sky, and the pattern of shade on the stream changed. Thermisters which began the experiment in sunlight move into shade, and vice versa, over the course of time. The data from the thermisters is presented in Table 2.

As an example, data from Table 2 is plotted in Figure 3. For clarity, only the readouts from 2 of the 10 thermisters are plotted, with indicators marking the approximate times when each was shaded. The temperature readout from each of the thermisters closely follows the other, showing no correlation with illumination by the Sun. In particular, thermister \#6 was illuminated for 6 continuous hours, and showed no drastic increase in the water temperature.

\section{Observations and Conclusions}

The theoretical analysis presented at the start of this paper, and the data presented in successive sections clearly show that the interpretation of the FLIR data for measuring stream temperatures is in error.

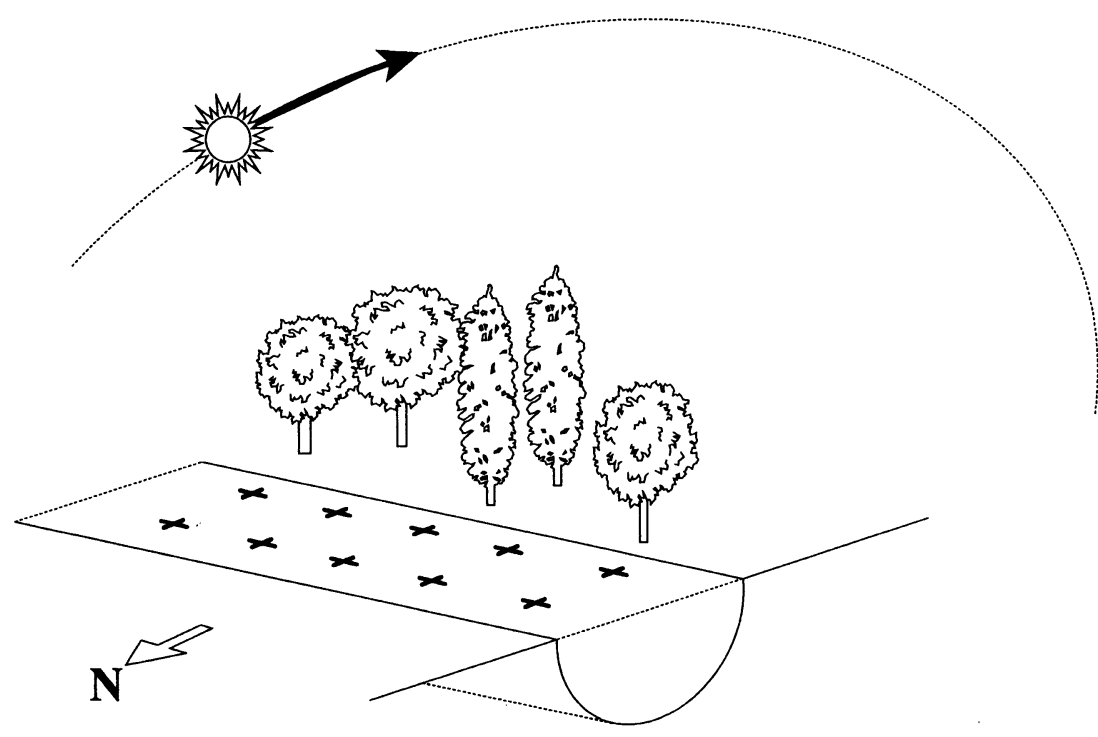

Fig. 2. The site for the experiment was along a stream channel running east west. The stream is shaded by a closed canopy for $1 \mathrm{~km}$ above the site and throughout the area where the temperature data was taken (canopy cover on the north side of the channel has been omitted from the figure for clarity). Ten thermisters were placed in $25 \mathrm{~cm}$ of water, every $3 \mathrm{~m}$ along both sides of the stream (marked by "+" at each location in the figure). The instruments recorded the temperature of the water once each hour. The daily motion of the Sun from east to west through the southern sky is indicated. As the position of the Sun changes, the pattern of shade and illumination on the stream channel changes, moving individual 
Table 2. Thermister Temperature Data, ${ }^{\circ} \mathrm{C}$. The cells of the table are shaded if the thermister was in shaded water at the time of the temperature measurement, and are unshaded if the thermister was in sunlit water at the time of the temperature measurement. The last row of the table, \% Sun, indicates what percentage of time during the experiment each thermister was in full sunlit water. All temperatures given in ${ }^{\circ} \mathrm{C}$.

\begin{tabular}{lrrrrrrrrrr}
\hline \hline & & & \multicolumn{8}{c}{ Thermister ID Number } \\
Time & $\# 1$ & $\# 2$ & $\# 3$ & $\# 4$ & $\# 5$ & $\# 6$ & $\# 7$ & $\# 8$ & $\# 9$ & $\# 10$ \\
\hline $5: 34$ & 10.0 & 10.0 & 9.9 & 9.9 & 9.9 & 9.8 & 9.9 & 9.9 & 9.9 & 9.9 \\
$6: 34$ & 9.4 & 9.4 & 9.6 & 9.6 & 9.6 & 9.4 & 9.6 & 9.6 & 9.6 & 9.6 \\
$7: 34$ & 9.4 & 9.4 & 9.2 & 9.2 & 9.3 & 9.2 & 9.3 & 9.2 & 9.3 & 9.2 \\
& & & & & & & & & & \\
$8: 34$ & 8.9 & 8.9 & 9.0 & 9.0 & 9.0 & 8.9 & 9.0 & 9.0 & 9.0 & 9.0 \\
$9: 34$ & 8.9 & 8.9 & 8.9 & 8.9 & 8.9 & 8.7 & 8.9 & 8.9 & 8.9 & 8.9 \\
$10: 34$ & 8.9 & 8.9 & 8.9 & 9.0 & 9.0 & 8.9 & 9.2 & 9.2 & 8.9 & 9.0 \\
$11: 34$ & 8.9 & 8.9 & 9.0 & 9.0 & 9.2 & 9.2 & 9.3 & 9.3 & 9.0 & 9.3 \\
$12: 34$ & 9.4 & 9.4 & 9.3 & 9.3 & 9.4 & 9.3 & 9.4 & 9.6 & 9.3 & 9.6 \\
$13: 34$ & 9.4 & 9.4 & 9.4 & 9.4 & 9.6 & 9.4 & 9.6 & 9.8 & 9.4 & 9.8 \\
$14: 34$ & 9.4 & 9.4 & 9.3 & 9.3 & 9.3 & 9.3 & 9.4 & 9.6 & 9.3 & 9.4 \\
$15: 34$ & 9.4 & 9.4 & 9.2 & 9.2 & 9.3 & 9.2 & 9.3 & 9.3 & 9.3 & 9.3 \\
$16: 34$ & 8.9 & 8.9 & 9.0 & 9.2 & 9.0 & 9.0 & 9.2 & 9.2 & 9.2 & 9.2 \\
$17: 34$ & 8.9 & 8.9 & 8.9 & 8.9 & 8.9 & 8.7 & 8.9 & 8.9 & 8.9 & 8.9 \\
\hline \% Sun & $50 \%$ & $67 \%$ & $42 \%$ & $17 \%$ & $33 \%$ & $50 \%$ & $42 \%$ & $58 \%$ & $58 \%$ & $50 \%$ \\
\hline
\end{tabular}

The most likely source of this error is that the data processing of the FLIR images has not accounted for all sources of infrared radiation, which should include: emitted radiation from the water, reflected radiation from the water (the reflected radiation could originate from several sources, be it direct radiation from the Sun, or reflected IR irradiance from the sky), and ambient sources of filtered radiation in the atmosphere and surrounding landscape scattering into the camera.

A possible argument against the results presented here is related to the question of what temperature FLIR data supposedly measures: the global temperature of the body of water, or the surface temperature of the water (Oregon Department of Environmental Quality (1999b)).

If FLIR data is a direct measure of the global water temperature, then the analysis presented here firmly demonstrates that the temperature interpretation (e.g., in Figure 1) is in error.

If FLIR data measures only the surface temperature of the water, then there are only 3 ways in which to interpret FLIR data as a monitor of water quality.

(1) The first possible interpretation is that the surface temperature of the water has nothing to do with the temperature of the water at depth. If this were the case, then FLIR data would be useless for monitoring water quality, and the technique should be abandoned.

(2) The second possibility is that the surface temperature of the water is relat- ed to the temperature at depth, but is not the same. If this were the case, then changes in surface temperature should mimic changes in temperature at below the surface (e.g., if the surface cools, the sub-surface water should also cool). As the analysis and data presented in this paper show, stream temperature does not change on short scales below the surface. As such, the suggestion of surface temperature changes on short scales by FLIR data is in no way correlated to the temperature below the surface, indicating an error in the FLIR interpretation.

(3) The last possibility is that surface temperature is exactly the same as the sub-surface temperature. If this is the case, monitoring the surface temperature is exactly the same as monitoring the temperature at depth. Again, the analysis and data presented in this work has shown that temperatures do not change on short scales, and the interpretation of the FLIR data is incorrect.

The use of airborne surveys of a watershed is a powerful technique for monitoring water quality. However, more robust methods will need to be developed if aerial imaging (in any spectrum) is to be used for monitoring water temperature. These techniques should be evaluated and tested against direct measurements of temperature in the streams themselves if they are going to be used to enforce regulatory policy.

\section{Full Sunlight vs. Intermittent Shade}

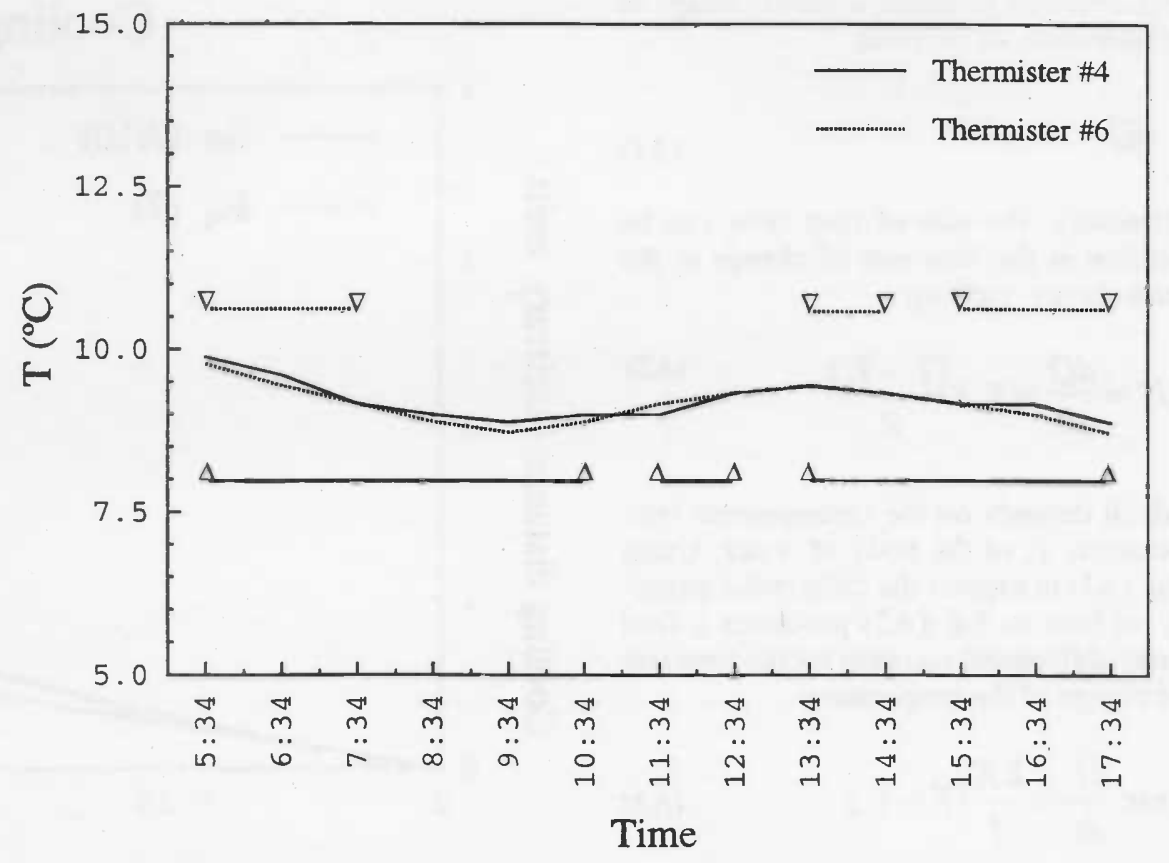

Fig. 3. A graph of the temperature readouts from 2 individual thermisters in the stream channel, showing the neglible effect of shade on the temperature. Solid lines between vertical triangles $(\Delta)$ indicate times when thermister \#4 was shaded. Dotted lines between inverted triangles indicate times when thermister \#6 was shaded. 


\section{APPENDIX: Robust Mathematical Treatment and Building Intuition}

The results presented in the body of this paper will tend to underestimate the effect of the cooling. This can be understood by considering the heat transfer described by Eq. (2). According to this equation, when the temperature difference between the system being cooled and the temperature of the thermal reservoir is large, then the rate at which heat energy is conducted is large as well. As the temperatures approach equilibrium, the flow of heat energy decreases, extending the time it will take for the system to cool completely to a state of equilibrium.

In the analysis previously presented (in the section 'The Effect of Water Flow on Temperature Profiles'), the rate of heat flow is always assumed to be maximal, at the rate the heat is transferred when the systems are first placed in thermal contact and cooling begins. A more robust estimate of the cooling distance can be derived by accounting for the change in water temperature over the course of the cooling process. This can be accomplished by taking differential forms of Eqs. (1) and (2), then integrating over the time the water is cooled.

Eq. (1) can be rewritten in differential form by writing the small amount of heat, $d Q$, required to create a small change in temperature, $d T$, to yield

$$
d Q=m c d T
$$

Similarly, the rate of heat flow can be written as the time-rate of change in the heat energy, yielding

$$
H=\frac{d Q}{d t}=k A \frac{\left(T-T_{r}\right)}{d}
$$

which depends on the instantaneous temperature, $T$, of the body of water. Using Eq. (A1) to express the differential quantity of heat in Eq. (A2) produces a first order differential equation for the time rate of change of the temperature:

$$
m c \frac{d T}{d t}=\frac{k A}{d}\left(T-T_{r}\right)
$$

This equation is separable, giving

$$
\frac{m c d}{k A} \frac{d T}{\left(T-T_{r}\right)}=d t
$$

which can be integrated over the entire cooling time:

$$
\frac{m c d}{k A} \int_{T_{i}}^{T f} \frac{d T}{\left(T-T_{r}\right)}=\int_{t_{i}}^{t f} d t
$$

The integrals are of a standard form and may be performed analytically, yielding an expression for the cooling time, $\Delta t$ :

$$
\Delta t=\frac{m c d}{k A} \ln \left[\frac{T_{f}-T_{r}}{T_{i}-T_{r}}\right]
$$

As before, this expression for the time may be converted into an expression for the cooling distance $\ell$ by using the definition of the speed the water flows, $\mathrm{v}=\ell / \Delta t$, to give

$$
\ell=\frac{v m c d}{k A} \ln \left[\frac{T_{f}-T_{r}}{T_{i}-T_{r}}\right]
$$

Again, replacing the mass yields $\mathrm{m}=\rho V=$ $\rho h A$ yields

$$
\ell=c \rho \frac{v h d}{k} \ln \left[\frac{T_{f}-T_{r}}{T_{i}-T_{r}}\right]
$$

(as

which has the same temperature structure as Eq. (7).

The result presented in Eq. (A10) is compared to that of Eq. (7) in Figure 4. As

\section{Cooling Distances}

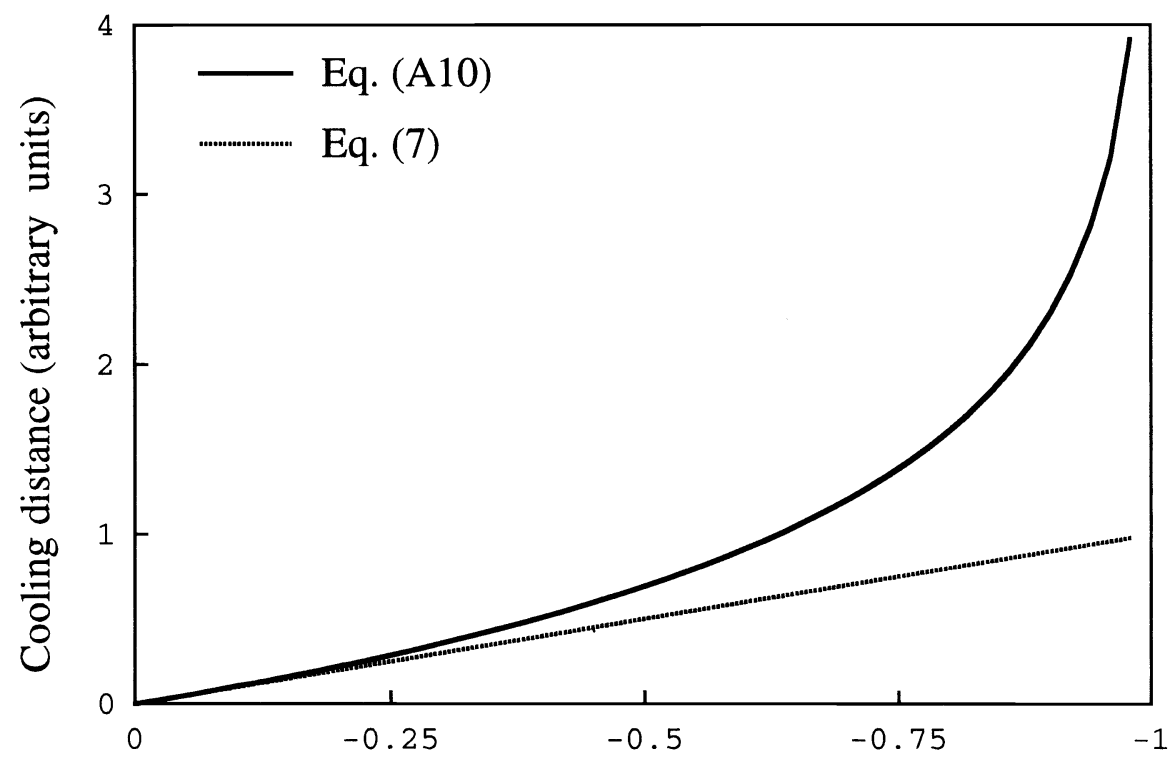

11

Fig. 4. Comparison of the cooling distances predicted by Eq. (7) and Eq. (A10), as a function of the quantity $u=\left(T_{f}-T_{i}\right) /\left(T_{i}-T_{r}\right)$. The $u$-axis covers only negative $u$ values, showing that only cooling processes are being considered (see text for details). As can be seen, the simple description offered by Eq. (7) underestimates the cooling distance for all possible cooling scenarios. 
can be seen, for all possible cooling scenarios, Eq. (7) underestimates the cooling distance. When is it valid to use Eq. (7) and not Eq. (A10)? If one identifies the parameter $\mathrm{u}=\left(T_{f}-T_{i}\right) /\left(T_{i}-T_{\mathrm{r}}\right)$, then the logarithm in Eq. (A10) may be expanded in a Taylor series

$$
\begin{aligned}
& \ln (1+u)=u-\frac{u^{2}}{2}+\frac{u^{3}}{3}-\frac{u^{4}}{4}+\cdots \\
& -1<u \leq+1
\end{aligned}
$$

If $|u|<<1$ (implying either a small required change in water temperature, a large temperature differential with the thermal reservoir, or both), then the logarithm is well approximated by the first term in the Taylor series, which yields Eq. (7). This relationship is apparent in Figure 3 , which shows the 2 functions roughly equal at small values of $u$.

The analysis presented here assumes that the water remains well mixed and of homogeneous temperature. If this condition is relaxed, then the analysis becomes much more difficult because of the presence of thermal gradients across the depth of the water. In this case, the analysis of the temperature evolution is governed by the onedimensional heat diffusion equation,

$$
\frac{\partial T}{\partial t}=\frac{k}{\rho c} \frac{\partial^{2} T}{\partial x^{2}}
$$

Understanding the implications of basic thermodynamic calculations, such as the ones presented in this paper, can be greatly enhanced by developing an intuitive sense of what the equations and results actually mean. Intuitive sense can be developed in 2 ways: by considering extreme limits, and through proportional reasoning.

As an example of an extreme limit to this calculation, one could consider that critics of water temperature regulation might remark that one should refrigerate the streams to meet temperature marks that regulatory agencies have specified for healthy stream environments. Initially, the idea of cooling a stream by technological means appears ludicrous, but the idea is one which can be explored within the context of this analysis to illuminate the difficulty of actually cooling a body of water. Because of its high specific heat, heat energy is not easily dissipated from a body of water. To demonstrate this, consider the following hypothetical situation, which demonstrates the difficulty of cooling water. Imagine refrigeration units could be installed in the streambed. This system would connect the water to a cooling reservoir at temperature $T_{r}=0^{\circ} \mathrm{C}$ through a metal which conducts heat very effectively (for example, copper which has a thermal conductivity of $\left.k=401 \mathrm{~W} /\left(\mathrm{m}^{\circ} \mathrm{C}\right)\right)$. In this purely idealized situation, the requisite distance to cool a stream (only $1 / 2$ meter deep) by $1^{\circ} \mathrm{C}$ would be $\ell \quad 62 \mathrm{~m}$.

When confronted by a result such as Eq. (7), it is often useful to expand the formula into an expression which depends only on the physical parameters which describe the system under consideration, in this case a stream in a watershed. This process allows one to understand in very simple terms, what will affect the transfer of heat energy in the system using proportional reasoning.

To simplify our understanding of the implications of Eq. (7), let us make the following identifications:

$\begin{array}{ll}\Delta T_{w}=T_{f}-T_{i} & \begin{array}{l}\text { change in water tempera- } \\ \text { ture }\end{array} \\ \Delta T_{o}=T_{f}-T_{r} & \begin{array}{l}\text { initial difference between } \\ \text { water temperature and } \\ \text { thermal reservoir }\end{array}\end{array}$

With these identifications, Eq. (7) may be rewritten as:

$$
\ell=c \rho \frac{v h d}{k} \frac{\Delta T_{w}}{\Delta T_{o}}
$$

The specific heat of water, $c$, and the density of water, $\rho$, are constants which cannot be changed, leaving only 6 parameters which might vary between any given stream. It is a simple matter to consider

\begin{tabular}{|c|c|c|}
\hline Parameter & Change & Effect on $\ell$ \\
\hline$v$ & $\begin{array}{l}\text { increase flow speed } \\
\text { decrease flow speed }\end{array}$ & $\begin{array}{l}\text { increase } \\
\text { decrease }\end{array}$ \\
\hline$h$ & $\begin{array}{l}\text { increase water depth } \\
\text { decrease water depth }\end{array}$ & $\begin{array}{l}\text { increase } \\
\text { decrease }\end{array}$ \\
\hline$d$ & $\begin{array}{l}\text { increase conduction layer } \\
\text { decrease conduction layer }\end{array}$ & $\begin{array}{l}\text { increase } \\
\text { decrease }\end{array}$ \\
\hline$k$ & $\begin{array}{l}\text { increase thermal conduction } \\
\text { decrease thermal conduction }\end{array}$ & $\begin{array}{l}\text { decrease } \\
\text { increase }\end{array}$ \\
\hline$\Delta T_{w}$ & $\begin{array}{l}\text { increase temperature change } \\
\text { decrease temperature change }\end{array}$ & $\begin{array}{l}\text { increase } \\
\text { decrease }\end{array}$ \\
\hline$\Delta T_{o}$ & $\begin{array}{l}\text { increase thermal gradient } \\
\text { decrease thermal gradient }\end{array}$ & $\begin{array}{l}\text { decrease } \\
\text { increase }\end{array}$ \\
\hline
\end{tabular}
what will increase and decrease the time (or in this case, the distance $\ell$ ) required to

Table 3. Effect of Change in Parameters on Cooling Distance proportional reasoning.

For direct proportionality, an increase in parameter value increases the distance over which the stream cools, and a decrease in value decreases the distance. For inverse proportionality, an increase in parameter value decreases the distance over which cooling occurs, while smaller values increase the cooling distance. For each of the 6 parameters in Eq. (7), their effects are summarized in Table 3 .

\section{Literature Cited}

Halliday, D. and R. Resnick. 1988. Fundamentals of Physics, Extended Third Edition. John Wiley \& Sons, New York.

Oregon Department of Environmental Quality. 1999a. Upper Grande Ronde River sub-basin temperature total maximum daily load (TMDL). Portland, Ore.

Oregon Department of Environmental Quality. 1999b. Tualitin basin temperature total maximum daily load (TMDL). Portland, Ore.

Serway, R. 1997. Physics for Scientists and Engineers with Modern Physics, Fourth Edition. Saunders College Publishing, New York. transfer heat energy out of a system using 